\title{
To ICSI or not to ICSI? That was the question
}

\author{
David F. Albertini
}

Published online: 30 December 2014

(C) Springer Science+Business Media New York 2014

Hard to believe that just about 20 years ago at the ESHRE meeting held in Thessalonika, Greece, the airwaves were buzzing concerning a breakthrough in human ARTs that would forever change the face of reproductive medicine. I happened to have been fortunate enough to be attending a precongress satellite meeting where Professor Andre van Stiertegen first presented the striking results generated at the Free University of Brussels demonstrating that successful development and pregnancy establishment was achieved using embryos made by intracytoplasmic sperm injection (ICSI), the somewhat serendipitous and paradigm-shifting finding of Gianpiero Palermo. Reaction to this announcement spanned the spectrum from incredulity to brilliance with a genuine retrospective attribution that has arguably conferred upon this breakthrough, the status of the most notable gamechanger in the short history of human ARTs.

Measured against the status quo of the day when the conversation with patients had more to do with how many eggs were fertilized rather than how many of your embryos will we transfer or freeze, ICSI put behind us the literal obstacles imposed by zona hardening or poor sperm motility. By placing blame for IVF failures on gametic inadequacies, ICSI technology rapidly spread from Brussels throughout the rest of the ART-practicing world only to launch again one of the many debates that would come to punctuate human ARTs then, and now: IVF versus ICSI? Or phrased another way, au naturel or high tech?

Capsule Advancing the cause of reproductive medicine, especially with regard to the treatment of infertility, positions emergent technologies for potential enhancements in the safety and efficacy of human ARTs. The final decision to proceed with adoption of one refinement or another often hinges on the publication of best case scenario observational findings that may or may not withstand the test of time.

D. F. Albertini $(\bowtie)$

University of Kansas Medical Center, Kansas, KS, USA

e-mail: dalbertini@kumc.edu
Think about how many of these "either-or"scenarios have been debated at meetings or in the pages of the most illustrious of scientific publications over the past 20 years. Ironically, as our technological progress has ranged far and wide in the spirit of better care for all, our palatal preferences for which approach should be adopted often takes on the character of the hard choices that must be made in a timely fashion but with a minimalist menu. For example, the tendency to proclaim one approach better than another, much like a face-off during a hockey game, predicts an outcome of indisputable proportions-even though the dynamic range or grey zone in biological systems frontally argues against "the one-size-fits-all" paradigm. Consider these ART face-offs from over the years: menopausal versus recombinant gonadotropins; zona hatching or not; day 3 or day 5 transfers; slow freeze or vitrify; high or low oxygen tension; SET or multiple embryo transfer; natural cycle versus $\mathrm{COH}$; and finally, fresh or frozen cycles being one of the latest courses added to the menu of ART delights. Such is the sum and substance of the content we hope JARG brings to our readership, and beginning in 2015 with this issue, we are pleased to offer a menu rich with choices and directions for the future practice of ARTs that, like fine wines, may present their true character in youth or in old age.

And speaking of old age, the arrival of some sense of appreciation for the pivotal role played by molecular oxygen during the development and expression of robust motility in sperm is the central theme of the review paper from Agarwal and his colleagues at the Cleveland Clinic that spares little in depth and thoroughness and most importantly carries the reader to a deeper understanding of the role of iron and copper in maintenance of male reproductive health. And speaking of molecular oxygen, and the ongoing debate concerning the impact of $20 \%$ atmospheric versus low oxygen tension for embryo culture, Paffoni and colleagues take a systematic approach in their evaluation of tolerance to high oxygen tension implying that while the detrimental effects resulting 
from the propagation of reactive oxygen species are generally accepted, exposures at early stages of development may be perceived by the embryo as not so harmful in the long run. Studies of this kind continue to point to the changing metabolic requirements exhibited by preimplantation human embryos, drawing attention once again to the debate over sequential versus single media strategies.

The latter theme seems not to have been settled when superimposed on the ongoing rage over the utility of time lapse (TL) imaging, a topic we suspect will loom substantively in the coming year. While TL systems have been deployed in the clinic for several years now, the market for such devices is morphing at a pace well in excess of the time needed to transform from a single cell zygote to that of an expanded blastocsyt as the diagnostic potential of the fourth dimension perception receives scrutiny from many angles. A novel multicenter study appears in JARG this month spearheaded by $\mathrm{Dr}$ Michael Diamond from the University of Georgia. Using a TL system that is, in relative terms, a newcomer on the scene, these telling studies take aim not only at the predictive value for embryo selection but attempt to analyze how "machine vision" compares to that of experienced embryologists when making the call for which embryos will gain entrance to the orifice of a transfer catheter.

As pointed out in the recent Fertility and Sterility webinar on TL imaging in the clinic (http://webinarjam.net/webinar/ go/replay/7952/b4ff22a0b0/qR3536318zK), matters of single media and non-disruptive handling of human embryos, when compared to conventional incubator approaches, may explain apparent benefits to embryo selection as reported by some laboratories whose efforts bespeak an emerging technology that may make the clinical grade after all.

In closing, we would like to acknowledge editorial board members who have served JARG well during its recent reincarnation. Nearly 6 years has passed since Springer and the ASRM joined hands to make JARG a force in the field of reproductive medicine. It has been my pleasure and honor to serve as the EIC during this time and thanks largely to the various Associate Editors and members of our editorial board, JARG has undergone enormous growth and a transformation that now makes it a go to journal for clinicians and scientists seeking to upgrade their understanding and practices of human ARTs past, present, and future. As we acknowledge elsewhere in this issue, without reviewers whose selfless commitment to JARG has effected both qualitative and quantitative improvements on a daily basis, we would not have realized the stature and ever growing perception that JARG now holds amongst those journals whose purview we complement and expand upon. Thank you to the many reviewers old and new that have contributed so much to the mission of JARG.

As we look to the future, there is a shared sense of optimism that to extend the momentum now in hand will require us to evaluate and rejuvenate our editorial board ranks. At this point we would like to recognize past members who played a foundational role in what has made JARG what it is today. Accordingly, our gratitude is extended to the following for their dedication to JARG:

Daniel DeMatos, Terry Hassold, Michael Holland, Hananel Holzer, Pat Hunt, Yves Menezo, Ajay Nangia,

Renee Reijo-Pera, Emre Seli, Sherman Silber, Johan Smitz, and Paulo Taitson.

Refreshing the editorial board affords the opportunity to expand upon our existing strengths in areas of great promise and change that will likely impact, and perhaps alter, the course of reproductive medicine well into the future. Besides the commitment board members make towards setting the bar for work published in JARG, their contributions extend deeply into the heart of manuscripts to aid our contributors as they mold their papers into ones that will receive the recognition deserved for true advancements in the field of human ARTs and reproductive genetics. Towards this end we welcome ten new board members who bring respected career accomplishments and standards of excellence that will shape the future of JARG. Our new members include:

Yaakov Bentov, Charles Borman, John Bromfield, Brian Dale, Marie-Madeleine Dolmans, Guoping Fan, Eric Forman, Elizabeth Ginsburg, Dean Morbeck, Stefania Nottola, and James H. Segars.

In addition, Catherine Racowsky and Jason Swain will now serve as Associate Editors bringing their first hand experience these past 6 years into the leadership and agenda setting roles that our AEs have tirelessly committed to.

Best wishes for a happy and healthy new year! 